\title{
Role of abrasive material on micro-abrasion wear tests
}

\author{
F.J.G. Silva, R.B. Casais, R.P. Martinho, A.P.M. Baptista
}

\begin{abstract}

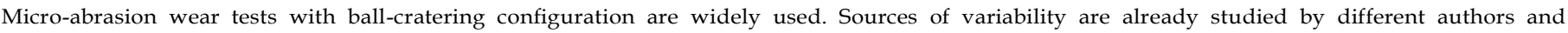

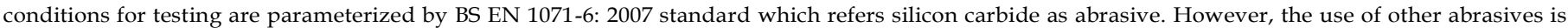

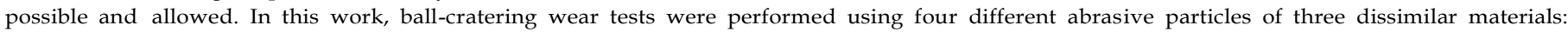

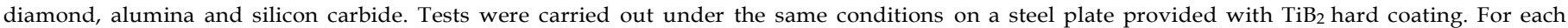

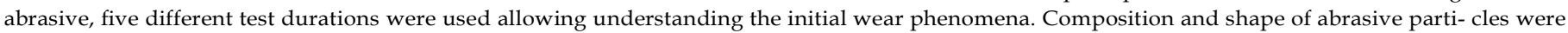

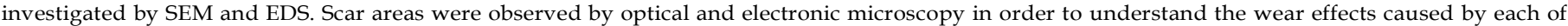

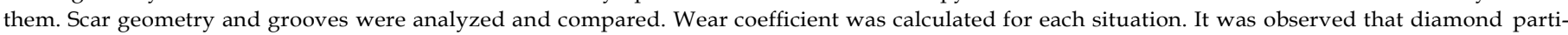

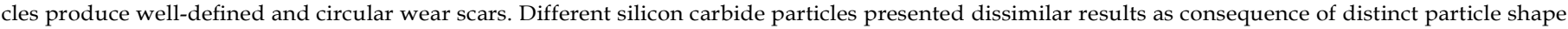
and size distribution.
\end{abstract}

\section{Keywords}

Micro-abrasion, Ball-cratering, $\mathrm{TiB}_{2}$ hard coating, Abrasive particles, Wear tests, Abrasive materials

\section{Introduction}

In the last decade, micro-abrasion wear tests using ball cratering configuration has been widely used in order to characterize wear behavior of thinhard coatings. Initially, thisconfiguration was used only for film thickness measurement but it was adapted to wear studies. This wear test takes advantage over others because coating thickness constrains the volume or depth of material that can be removed before the coating is perforated [1]. Furthermore, this test is quick, convenient, can be performed on small samples and uses relatively inexpensive equipment [2]. Otherwise, reliability and reproducible measurements [3] ensure that this wear test configuration meets the requirements sought by investigators, if test conditions used are the same. However, wear rates and wear mechanisms can differ significantly when test conditions change, as normal load or sliding speed [4,5]. Authors refer [3] that two wear modes can be achieved during micro-abrasion wear tests: 'three-body' abrasion and 'two-body' abrasion. The wear modecan be changed adjusting the load or selecting other abrasive particles [6], the abrasive content in the slurry [7] and the ball surface condition [8]. Concerning the ball surface condition, Stachowiak et al. [9] referred that soft materials were more affected by ball surface roughness than harder materials. Adachi and Hutchings [10] proposed critical conditions for the transition from 'three-body' to 'two-body', allowing predicting the wear mode in practical tests.

Many efforts has been done in order to establish the best wear test parameters and study its influence in the results [2,10-14], which subsequently gave rise to BS-EN 1071-6: 2007 standard. Before this, many devoted authors have compiled a great number of testing results in order to validate the micro-abrasion wear test [15]. This standard recommends SiC F1200 as abrasive particles, but does not restrict the use of other abrasives or grain sizes, since less than $5 \mu \mathrm{m}$. Before the standard publication, other author made some studies in order to investigate the influence of grain size in micro-abrasion wear tests $[9,16]$.

Some authors $[9,10,12,16,17]$ recognize that particles shape strongly influences the particle motion in the contact. However, abrasive particles material also plays an important role in the micro-abrasion process. Furthermore, due to coating hardness, some works could not use silicon carbide or alumina $[18,19]$.

Schiffmann et al. tested different slurries in free ball-cratering configuration, referring that the solution of $\mathrm{Al}_{2} \mathrm{O}_{3}$ in glycerin is more suitable for non-perforating tests [14]. It should be taken into account that, if hardness of abrasive particles is to much higher than the coating to be tested, crater depth increases substantially, facilitating abrasive particles entrainment, contributing to non-linearity 
Table 1

Chemical composition of CK45 steel (\%wt).

\begin{tabular}{llllllll}
\hline $\mathrm{C}$ & $\mathrm{Mn}$ & $\mathrm{Si}$ & $\mathrm{Cr}$ & $\mathrm{Mo}$ & $\mathrm{Ni}$ & $\mathrm{P}$ & $\mathrm{S}$ \\
\hline $0.44 \%$ & $0.53 \%$ & $0.14 \%$ & $0.044 \%$ & $0.005 \%$ & $0.047 \%$ & $0.013 \%$ & $0.02 \%$ \\
\hline
\end{tabular}

of the results [9]. Abrasive particles shape also takes an important role in this process.

In this work, some different abrasive materials were investigated in order to understand the different action of each one. Particleshapeand grainsizewereanalyzed.Using thesamecoating, wear coefficient was calculated for each situation.

\section{Experimental details}

\subsection{Samples preparation}

In order to carry out this work, square samples of $25 \mathrm{~mm} \times 25 \mathrm{~mm} \times 2 \mathrm{~mm}$ of CK45 hot rolled steel were cut. The steel chemical composition can be observed in Table 1. Hardness of the substrates was measured using an EMCOM4U 025 Universal Hardness Tester was 205HBW 2.5/187.5/5. Samples were cut, milled, ground and mechanically polished with $3 \mu \mathrm{m}$ diamond powder during $15 \mathrm{~min}$ in order to obtain smooth sample surfaces. At this point, surface morphology and roughness were analyzed by Atomic Force Microscopy (AFM) technique, using VEECO Multimode equipment ( $7 \mathrm{~nm}$ tip radius) provided with NanoScope 6.13 software. Two different analysis areas were used: $10 \mu \mathrm{m} \times 10 \mu \mathrm{m}$ and $50 \mu \mathrm{m} \times 50 \mu \mathrm{m}$. Arithmetic mean roughness and maximum roughness obtained by these analyses were $R_{a}=0.0121 \mu \mathrm{m}$ and $R_{t}=0.0684 \mu \mathrm{m}$, respectively.

\subsection{Coating process}

Prior to deposition, samples were cleaned in an ultrasonic bath during $20 \mathrm{~min}$. Hereafter, samples have been assembled in the PVD machine holder. Before deposition, sputter-cleaning process was done, in order to make the surface free of contaminants. Coating process was carried out in a CemeCon CC800/9ML PVD Magnetron Sputtering system, using the unbalanced magnetron sputtering technique, provided with four targets of $\mathrm{TiB}_{2}$ alloy. Deposition was assisted by $\mathrm{Ar}^{+}$. Deposition parameters used in the deposition are the following: substrate temperature of $450{ }^{\circ} \mathrm{C}$, pressure inside the reactor, 500 mbar, current intensity in the targets, $20 \mathrm{~A}$, time deposition, $210 \mathrm{~min}$ and rotational holder speed, 1 revolution per minute.

\subsection{Coating morphological characterization}

After deposition, one of the samples was cut in the reverse side of the coating and mechanically cracked, in order to observe its structure. Other sample was subject to metallurgical preparation, allowing accurately measuring the film thickness. In order to carry out these observations, a FEI Quanta 400FEG scanning electron microscope (SEM) provided with an EDAX Genesis X-ray spectroscope (EDS) was used. Confirming the SEM morphological analysis, atomicforcemicroscopy (AFM) analyses weremadeusing

the equipment and software above referred. $10 \mu \mathrm{m} \times 10 \mu \mathrm{m}$ and $50 \mu \mathrm{m} \times 50 \mu \mathrm{m}$ AFM analyses were made, using the tapping mode.

Hardness measurements were carried out in a micro-hardness Fischerscope ${ }^{\mathrm{TM}} \mathrm{H} 100$ equipment. Selected rangeload was $0-50 \mathrm{mN}$ and the maximum load was kept constant during $30 \mathrm{~s}$ (avoiding

creep phenomena). This equipment produces values chart that allows obtaining 'load-depth' curves, conducting to hardness and Young's modulus values. Measurements were made using a Vickers indenter.
Table 2

Micro-abrasion test parameters.

\begin{tabular}{ll}
\hline Parameters & \\
\hline Rotation speed $\left[\mathrm{m} \mathrm{s}^{-1}\right]$ & 0.105 \\
Normal load [N] & 0.20 \\
Tests duration [Rev.] & $25,50,100,200$ and 400 \\
Corresponding sliding distances [m] & $1.96,3.93,7.86,15.71,31.42$ \\
Abrasive concentration $\left[\mathrm{g} \mathrm{ml}^{-1}\right]$ & $6.4 / 98$ \\
Abrasive particles used & Diamond, alumina and SiC \\
Average grains size $[\mu \mathrm{m}]$ & $1-5$ \\
\hline
\end{tabular}

\subsection{Adhesion test}

Rockwell indentation tests were made in order to verify the adhesion between coating and substrate. These tests were done inanEMCOM4U Universal Hardness Tester using 49N (5kgf), 98N (10 kgf), $294 \mathrm{~N}$ (30 kgf) and $980 \mathrm{~N}$ (100 kgf) with diamond tip Rockwell indenter. Rockwell test procedure was carried out as specified in VDI 3198: 1991 standard. Indentations were observed using the above mentioned SEM equipment. Results were compared with illustrations and failure modes illustrated in the standard, allowing the classification of the failure pattern obtained.

\subsection{Micro-abrasion tests}

Characterization of wear produced by each kind of abrasive particles was done using a PLINT TE 66 micro-abrasion wear tester, using a fixed ball cratering configuration. This test uses a SAE 52100 steel ball with $25 \mathrm{~mm}$ diameter, acting as counter body during the wear tests, dragging over the sample coated surface the abrasive particles contained in previously prepared slurry. This ball, initially in polished state, was etched in a $10 \%$ NITAL solution during $20 \mathrm{~s}$, in order to increase its surface roughness to allow better abrasive particles dragging process. Abrasive slurry is constantly dripped into the contact between the ball and the sample all over the test. As stipulated by BS EN 1071-6:2007 standard, slurry was composed by $6.4 \mathrm{~g}$ of abrasive particles to $98 \mathrm{ml}$ of distilled water. With this concentration, grooving wear was expected. Remaining test parameters can be seen in Table 2. After each wear test, ball was changed of position, avoiding non-linear results caused by increased roughness of the track drawn in the ball surface.

As abrasive particles three different materials were selected:

Diamond, $\mathrm{Al}_{2} \mathrm{O}_{3}$ and $\mathrm{SiC}$. Due to low film thickness, small grain abrasive particles size was chosen. Two different SiC particles were used, allowing comparing its performance in micro-abrasion wear tests: the first one classified as F1000 by FEPA (Federation of European Producers of Abrasives), with average size particles of $5.5 \mu \mathrm{m}$ but large standard deviation and another one, F1200, with about $3.4 \mu \mathrm{m}$ of average grain size and $1.4 \mu \mathrm{m}$ of standard deviation. The grain size and standard deviation of the different abrasive particles used in this work is shown in Table 3.

Tests with five different durations were carried out, allowing understanding micro-abrasion evolution and failure mechanisms, before and after perforation. Then, attending the abrasivity of the diamond, runs of 25,50, 100, 200 and 400 revolutions were established. Tests were performed three times for each duration and abrasive.

Table 3

Abrasive particles grain size.

\begin{tabular}{lll}
\hline Material & Average size $(\mu \mathrm{m})$ & Deviation $(\mu \mathrm{m})$ \\
\hline Diamond & 1.0 & 0.6 \\
Alumina & 1.0 & 0.5 \\
SiC F1000 & 5.5 & 4.5 \\
SiC F1200 & 3.4 & 1.4 \\
\hline
\end{tabular}



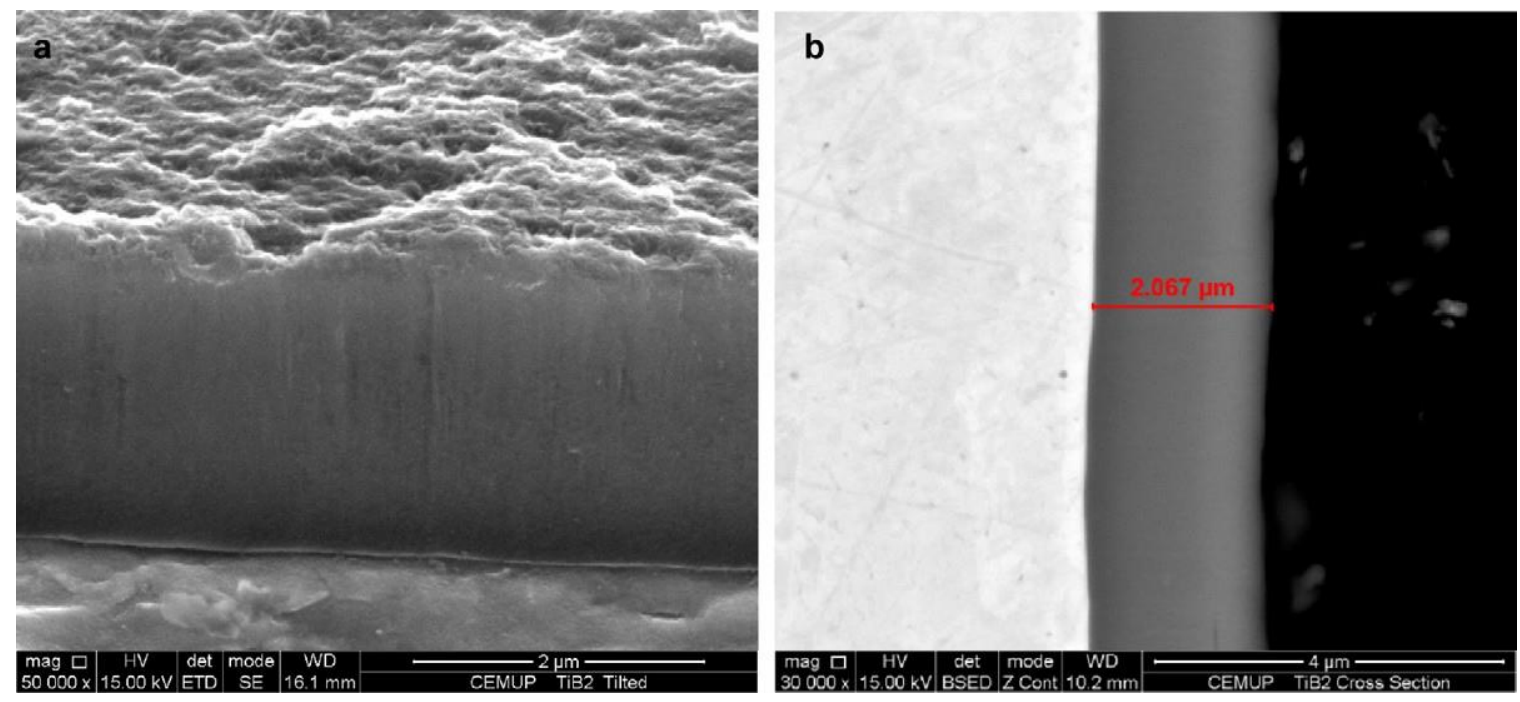

Fig. 1. Cross-section views of $\mathrm{TiB}_{2}$ coating showing (a) the morphology and structure and (b) the thickness of the coating.

After wear tests, craters produced were carefully analyzed by SEM, using the above referred equipment. An equivalent circle was drawn in each crater, taking into account the density of detachment events around the well-defined crater.

\section{Results and discussion}

Coating process results in a monolayer thin film, as can be observed in Fig. 1, with $\sim 2.1 \mu \mathrm{m}$ thickness and a typical texture of $\mathrm{TiB}_{2}$ coatings. Cross-section view, obtained by SEM after mechanical cracking, allows observing that film structure is extremely homogeneous and presents a columnar orientation. Morphology of the film presents some grooves randomly dispersed, which is characteristic of the $\mathrm{TiB}_{2}$ ind ustrial coatings. PVD sputtering deposition rate for this type of film is less than others such as TiAlN, TiAlSiN or TiAlCrN obtained with the same parameters set. The surface natural grooves can be observed in Fig. 2, acquired using atomic force microscopy. Despite of this, the measured average mean roughness obtained by this technique was $4.06 \mathrm{~nm}$ and the maximum roughness was $5.24 \mathrm{~nm}$, using an analyzed area of $10 \mu \mathrm{m}$ $10 \mu \mathrm{m}$, which would be considered as very smooth surface.

Due to low film thickness, coating hardness could be accessed using extra low load in the micro-hardness tester. As well-known, indentation tests depth cannot exceed $10 \%$ of film thickness; otherwise, hardness results would be influenced by substrate. Then, indentations were produced with $50 \mathrm{mN}$ normal load. Hardness value obtained was $26.82 \mathrm{GPa}$, which is lower than some values

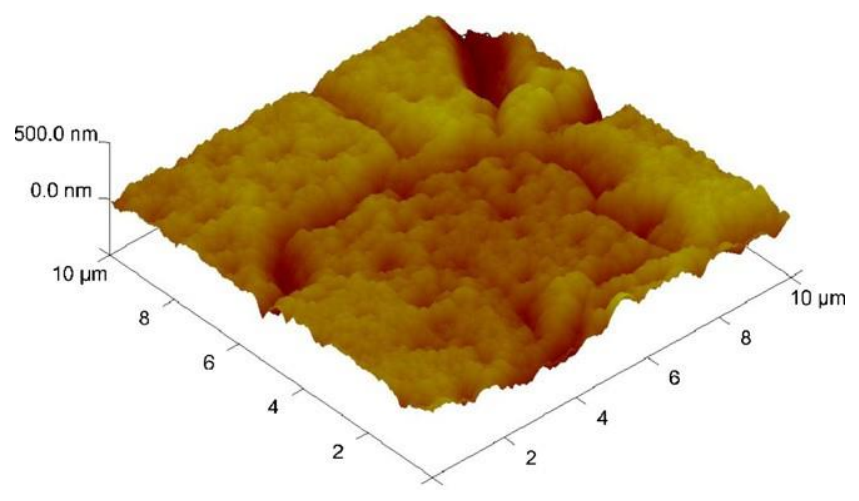

Fig. 2. AFM $3 \mathrm{D}$ analysis of the $\mathrm{TiB}_{2}$ coating morphology. referred by other authors for the same coating. Young's modulus $(E)$ registered was $343.4 \mathrm{GPa}$ and Young's modulus reduced $\left(E_{r}\right)$ was 270.26 GPa.

Fig. 3 evince the abrasive particles morphology. As can be observed, Diamond and $\mathrm{Al}_{2} \mathrm{O}_{3}$ presents similar grain size and homogeneity, when $\mathrm{SiC}$ particles exhibithigh grain size and heterogeneity. When diamond and $\mathrm{SiC}$ particles present irregular shape and high angularity, $\mathrm{Al}_{2} \mathrm{O}_{3}$ shows regular and smooth shape.

Fig. 4 depicts the low abrasivity of the $\mathrm{Al}_{2} \mathrm{O}_{3}$ particles. Both after 25 and 400 cycles, $\mathrm{TiB}_{2}$ coating resists to micro-abrasion and it is clear that no film perforation can be observed, even for the longest test duration selected. After 25 cycles, worn area shows polished aspect, while after 400 cycles, deep grooves are obvious. Analyzing all the scars produced with $\mathrm{Al}_{2} \mathrm{O}_{3}$ abrasive, it is possible to conclude that the first grooves appear between 25 and 50 cycles. After that, initial smooth grooves tend to increase its depth and new smooth grooves start its formation. Low abrasivity of the $\mathrm{Al}_{2} \mathrm{O}_{3}$ particles can be attributed to its relatively low hardness and rounded shape of the particlescontour.

Fig. 5 shows the craters produced by diamond particles. In this case, perforation of the $\mathrm{TiB}_{2}$ coating was obtained before 25 cycles. Despite this short sliding distance, the crater produced with 25 cycles yields to believe that perforation occurs after a few number of ball revolutions. Then, perforation was evident in all the tests carried out with diamond particles. Notwithstanding grain size of diamond and $\mathrm{Al}_{2} \mathrm{O}_{3}$ particles to be similar, high hardness and aggressive contour of the particles produced higher micro-abrasion. Deep grooves are perceptible and craters begin as ill-defined for low number of cycles (short sliding distance) and tend to well-defined increasing the test duration. Grooves tend to be deeper in the way out side of the abrasive particles. This phenomenon can be attributed to the concentration of abrasive particles during the contact. Observing the craters, it seems that we are in presence of a mix wear mode situation, where diamond particles had been rolled by the grooves, in a channeling process, accentuating the wear and enlarging the grooves ("three-body" wear mechanism) and some particles embedded in the ball surface that acted as "two-body" wear mechanism [3,20].

Micro-abrasion wear tests carried out with SiC F1000 abrasive particles produced irregular craters, with deep grooves welldefined. In the border of these craters, there are many film detachments. These lateral damages could be originated by large abrasive particles included in the slurry. It can be noted that this abrasive presents high heterogeneity, with some particles with 

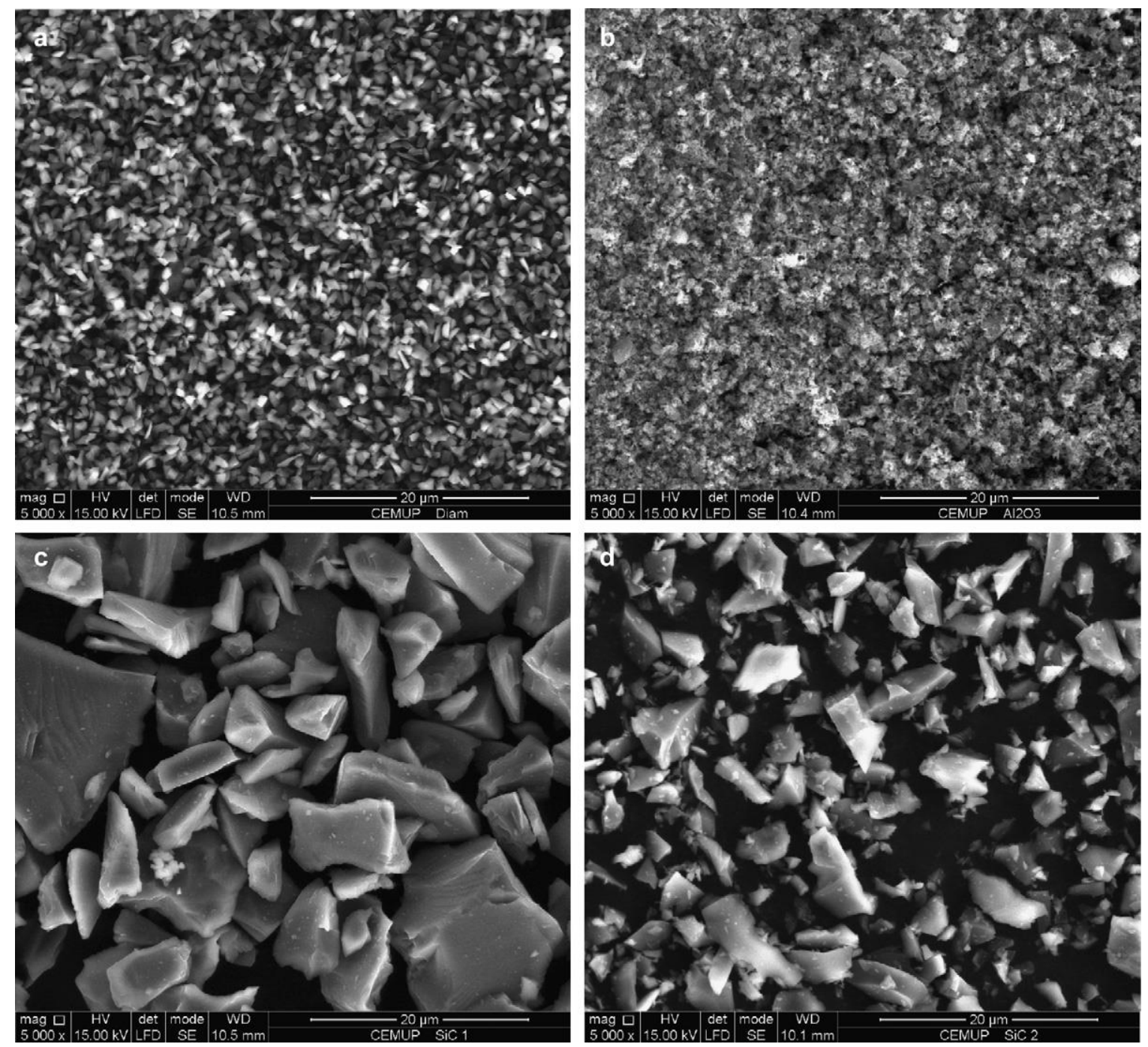

Fig. 3. Abrasive particles morphology: (a) diamond, (b) alumina, (c) SiC F1000 and (d) SiC F1200 shown with the same magnification (5000 $\times$ ).

Table 4

Data corresponding to micro-abrasion wear tests.

\begin{tabular}{|c|c|c|c|c|c|c|c|c|}
\hline $\begin{array}{c}\text { Thickness }[\mu \mathrm{m}] \\
2,1\end{array}$ & Cycles & $\mathrm{SN}$ & $\begin{array}{l}V_{c} \\
{\left[\mathrm{~mm}^{3}\right]}\end{array}$ & $\begin{array}{l}V_{c} \\
{\left[\mathrm{~mm}^{3}\right]}\end{array}$ & $\begin{array}{l}V_{s} \\
{\left[\mathrm{~mm}^{3}\right]}\end{array}$ & $\begin{array}{l}V_{c}+V_{s} \\
{\left[\mathrm{~mm}^{3}\right]}\end{array}$ & $\begin{array}{l}\mathrm{SN} / V_{c} \\
{\left[\mathrm{~N} \mathrm{~m} \mathrm{~mm} \mathrm{~mm}^{-3}\right]}\end{array}$ & $V_{s} / V_{c}$ \\
\hline $\mathrm{AI}_{2} \mathrm{O}_{3}$ & 25 & 0.49 & & $5.39 E-06$ & & & & \\
\hline $\mathrm{AI}_{2} \mathrm{O}_{3}$ & 50 & 0.98 & & $2.02 \mathrm{E}-05$ & & & & \\
\hline $\mathrm{AI}_{2} \mathrm{O}_{3}$ & 100 & 1.96 & & $3.31 \mathrm{E}-05$ & & & & \\
\hline $\mathrm{AI}_{2} \mathrm{O}_{3}$ & 200 & 3.93 & & $4.44 \mathrm{E}-05$ & & & & \\
\hline $\mathrm{AI}_{2} \mathrm{O}_{3}$ & 400 & 7.85 & & $1.16 \mathrm{E}-04$ & & & & \\
\hline Diamond & 25 & 0.49 & $2.85 \mathrm{E}-04$ & $2.71 \mathrm{E}-04$ & $1.39 \mathrm{E}-05$ & $2.85 \mathrm{E}-04$ & $1.81 \mathrm{E}+03$ & $5.11 \mathrm{E}-02$ \\
\hline Diamond & 50 & 0.98 & $4.02 \mathrm{E}-04$ & $3.68 \mathrm{E}-04$ & 5.47E-05 & $4.22 \mathrm{E}-04$ & $2.67 \mathrm{E}+03$ & $1.49 \mathrm{E}-01$ \\
\hline Diamond & 100 & 1.96 & $6.24 \mathrm{E}-04$ & $5.94 \mathrm{E}-04$ & $2.55 \mathrm{E}-04$ & $8.49 \mathrm{E}-04$ & $3.31 \mathrm{E}+03$ & $4.30 \mathrm{E}-01$ \\
\hline Diamond & 200 & 3.93 & $8.33 \mathrm{E}-04$ & $8.48 \mathrm{E}-04$ & $6.58 \mathrm{E}-04$ & $1.51 \mathrm{E}-03$ & $4.63 E+03$ & $7.76 \mathrm{E}-01$ \\
\hline Diamond & 400 & 7.85 & $1.43 E-03$ & $1.44 \mathrm{E}-03$ & $2.32 \mathrm{E}-03$ & $3.76 \mathrm{E}-03$ & $5.45 \mathrm{E}+03$ & $1.61 \mathrm{E}+00$ \\
\hline SiCF1200 & 25 & 0.49 & & $5.82 \mathrm{E}-04$ & $2.42 \mathrm{E}-04$ & $8.24 \mathrm{E}-04$ & $8.43 E+02$ & $4.15 \mathrm{E}-01$ \\
\hline SiCF1200 & 50 & 0.98 & & $6.74 \mathrm{E}-04$ & $3.62 \mathrm{E}-04$ & $1.04 \mathrm{E}-03$ & $1.46 \mathrm{E}+03$ & $5.38 \mathrm{E}-01$ \\
\hline SiCF1200 & 100 & 1.96 & & $9.41 \mathrm{E}-04$ & $8.52 \mathrm{E}-04$ & $1.79 \mathrm{E}-03$ & $2.09 \mathrm{E}+03$ & $9.05 \mathrm{E}-01$ \\
\hline SiCF1200 & 200 & 3.93 & & $1.24 \mathrm{E}-03$ & $1.63 \mathrm{E}-03$ & $2.86 \mathrm{E}-03$ & $3.18 \mathrm{E}+03$ & $1.32 \mathrm{E}+00$ \\
\hline SiCF1200 & 400 & 7.85 & & $1.62 \mathrm{E}-03$ & $3.02 E-03$ & $4.64 \mathrm{E}-03$ & $4.85 \mathrm{E}+03$ & $1.87 \mathrm{E}+00$ \\
\hline SiCFIOOO & 25 & 0.49 & & $1.10 \mathrm{E}-03$ & $1.23 \mathrm{E}-03$ & $2.33 \mathrm{E}-03$ & $4.47 \mathrm{E}+02$ & $1.12 \mathrm{E}+00$ \\
\hline SiCFIOOO & 50 & 0.98 & & $1.22 \mathrm{E}-03$ & $1.58 \mathrm{E}-03$ & $2.80 \mathrm{E}-03$ & $8.05 E+02$ & $1.30 \mathrm{E}+00$ \\
\hline SiCFIOOO & 100 & 1.96 & & $1.35 \mathrm{E}-03$ & $2.01 \mathrm{E}-03$ & $3.37 \mathrm{E}-03$ & $1.45 \mathrm{E}+03$ & $1.49 \mathrm{E}+00$ \\
\hline SiCFIOOO & 200 & 3.93 & & $1.84 \mathrm{E}-03$ & $4.03 E-03$ & $5.87 \mathrm{E}-03$ & $2.13 E+03$ & $2.19 \mathrm{E}+00$ \\
\hline SiCFIOOO & 400 & 7.85 & & $2.32 \mathrm{E}-03$ & $6.66 \mathrm{E}-03$ & $8.98 \mathrm{E}-03$ & $3.38 \mathrm{E}+03$ & $2.87 \mathrm{E}+00$ \\
\hline
\end{tabular}



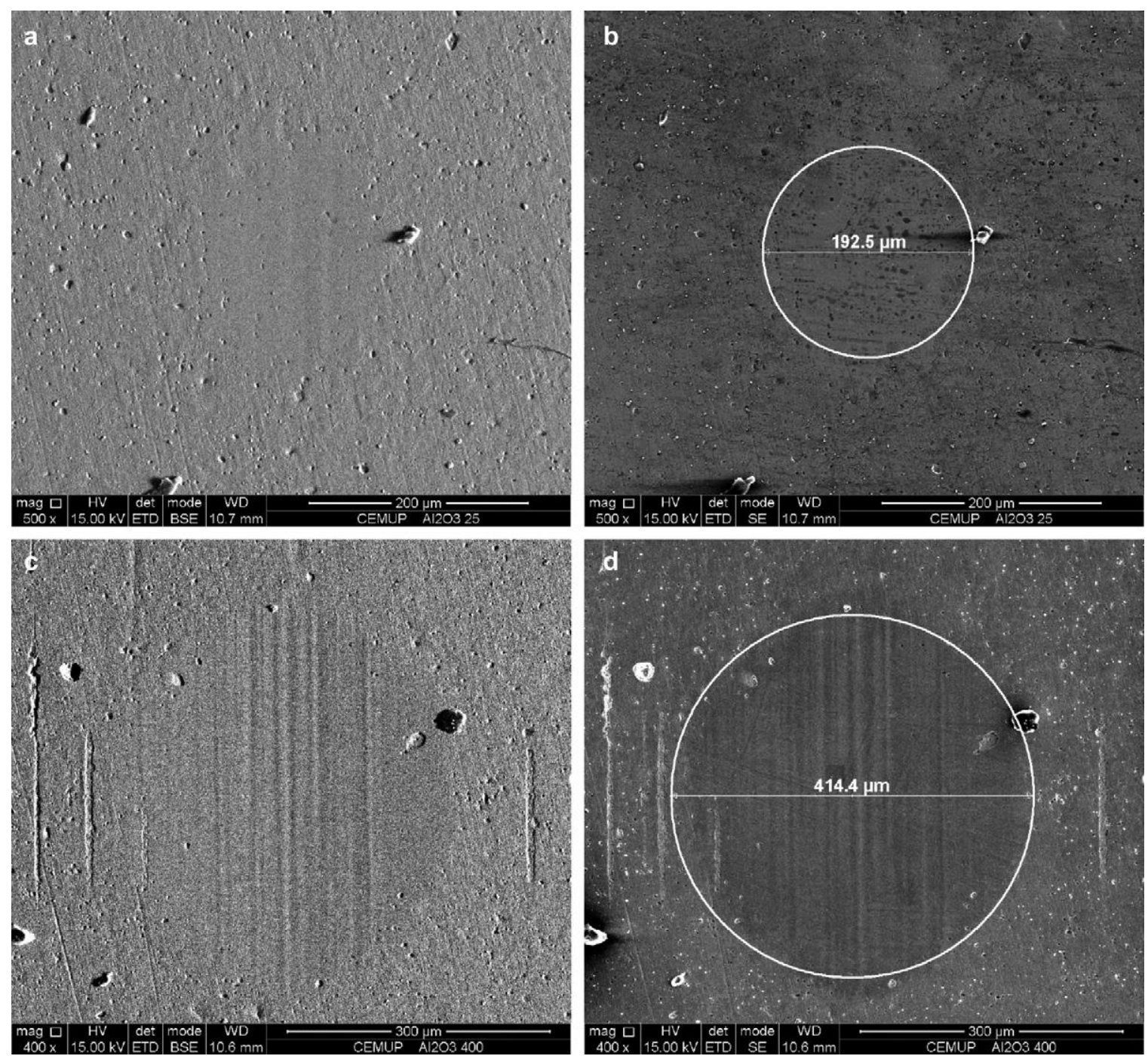

Fig. 4. Craters produced in the $\mathrm{TiB}_{2}$ coating ((a) and (b)) after 25 cycles (1.96 m sliding distance) with $\mathrm{Al}_{2} \mathrm{O}_{3}$ abrasive particles and ((c) and (d)) after 400 cycles ( $31.42 \mathrm{~m}$ sliding distance) with the same abrasive, under different SEM view modes.

$10 \mu \mathrm{m}$. Then, craters do not present a well-defined border neither a clear slope between the inner and overall borders. In this case, inner and overall crater diameters were considered the same, for wear calculation purposes, due to natural difficulty to measure the external contour. The formation of these borders can result of the conjunction of three factors: thin film thickness, high coating hardness and large abrasive particles present in the slurry. Craters diameter using this abrasive are similar to those achieved with diamond particles. Attending that $\mathrm{SiC}$ hardness is lower than diamond hardness, these results can be attributed mainly to abrasive grain size. As depicted in Fig. 6, film perforation was done after a low number of cycles because, after 25 cycles, crater present high diameter and well-defined grooves. The wear process is accented for tests carried out with SiC F1000 abrasive, as referred in further discussion.

Wear tests performed with $\mathrm{SiC}$ F1200 originated lower crater diameters than SiC F1000. Crater borders also hold many coating detachments and present ill-defined contour, as can be observed in Fig. 7. Deep grooves are obvious in all the scars and there is a clear difficulty in discerning the overall border, even using differentSEM observation modes. Craters diameter and removed material were lower than observed with SiC F1000 in the same micro-abrasion wear test conditions.
Data corresponding to wear micro-abrasion tests are presented in Table 4 . The wear coefficient $\left(k_{c}\right)$ and wear resistance $\left(k_{c}{ }^{-1}\right)$ related with the abrasives where coating perforation was verified, were determinate using Kusano et al. [21] methodology and nomenclature, where $S$ means the sliding distance $(\mathrm{m}), N$ the normal load $(\mathrm{N}), V_{s}$ the substrate volume removed $\left(\mathrm{mm}^{3}\right)$ and $V_{c}$ the coating volume removed $\left(\mathrm{mm}^{3}\right)$. In Fig. 8, data is plotted for the different test durations used in this work, in order to determine the average wear coefficient and wear resistance for each kind of abrasive. For $\mathrm{Al}_{2} \mathrm{O}_{3}$ abrasive, no perforation was observed and, in this case, traditional wear coefficient and wear resistance calculations were done, according to BS EN 1071-6: 2007 standard and Archard equation $(k=V /(S N))$.

Table 5

Ratio between hardness (coating and abrasive particles), wear resistance and wear coefficient.

\begin{tabular}{llllcl}
\hline Abrasive & $\begin{array}{l}H_{a} \\
\mathrm{GPa}\end{array}$ & $\begin{array}{l}H \\
\mathrm{GPa}\end{array}$ & $H_{a} / H$ & $\begin{array}{l}k_{c}{ }^{-1} \\
{\left[\mathrm{~N} \mathrm{~m} \mathrm{~mm} \mathrm{~mm}^{-3}\right]}\end{array}$ & $\begin{array}{l}k_{c} \\
{\left[\mathrm{~mm}^{3} \mathrm{~N}^{-1} \mathrm{~m}^{-1}\right]}\end{array}$ \\
\hline $\mathrm{Al}_{2} \mathrm{O}_{3}$ & 16.50 & 26.82 & 0.62 & 71041 & $1.41 \mathrm{E}-5$ \\
Diamond & 80.00 & 26.82 & 2.98 & 2241 & $4.46 \mathrm{E}-4$ \\
$\mathrm{SiCF}$ 1200 & 24.00 & 26.82 & 0.89 & 182 & $5.49 \mathrm{E}-3$ \\
$\mathrm{SiCF} 1000$ & 24.00 & 26.82 & 0.89 & 1209 & $8.27 \mathrm{E}-4$ \\
\hline
\end{tabular}



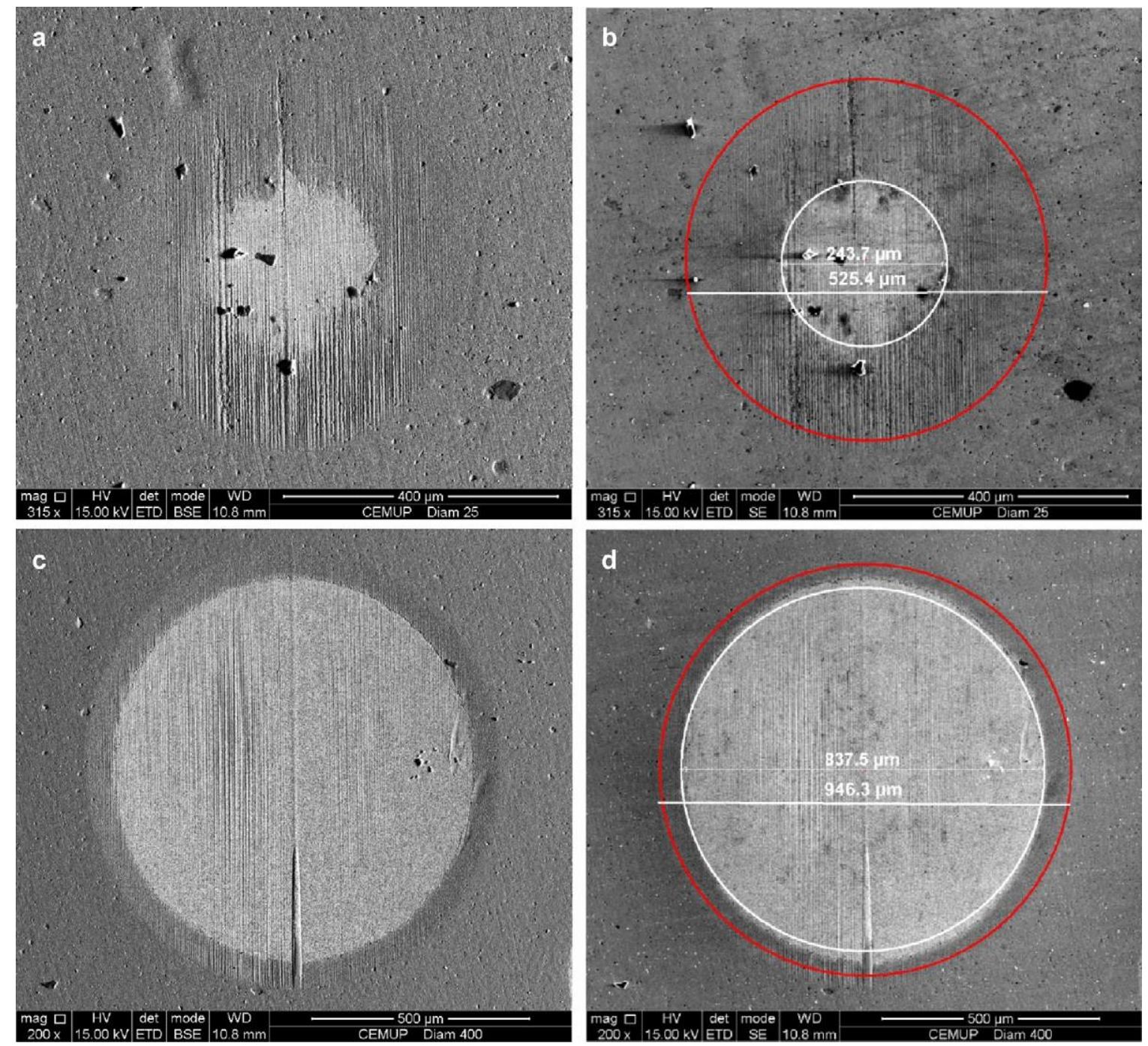

Fig. 5. Craters produced in the $\mathrm{TiB}_{2}$ coating ((a) and (b)) after 25 cycles (1.96 m sliding distance) with Diamond abrasive particles and ((c) and (d)) after $400 \mathrm{cycles}(31.42 \mathrm{~m}$ sliding distance) with the same abrasive, under different SEM view modes.
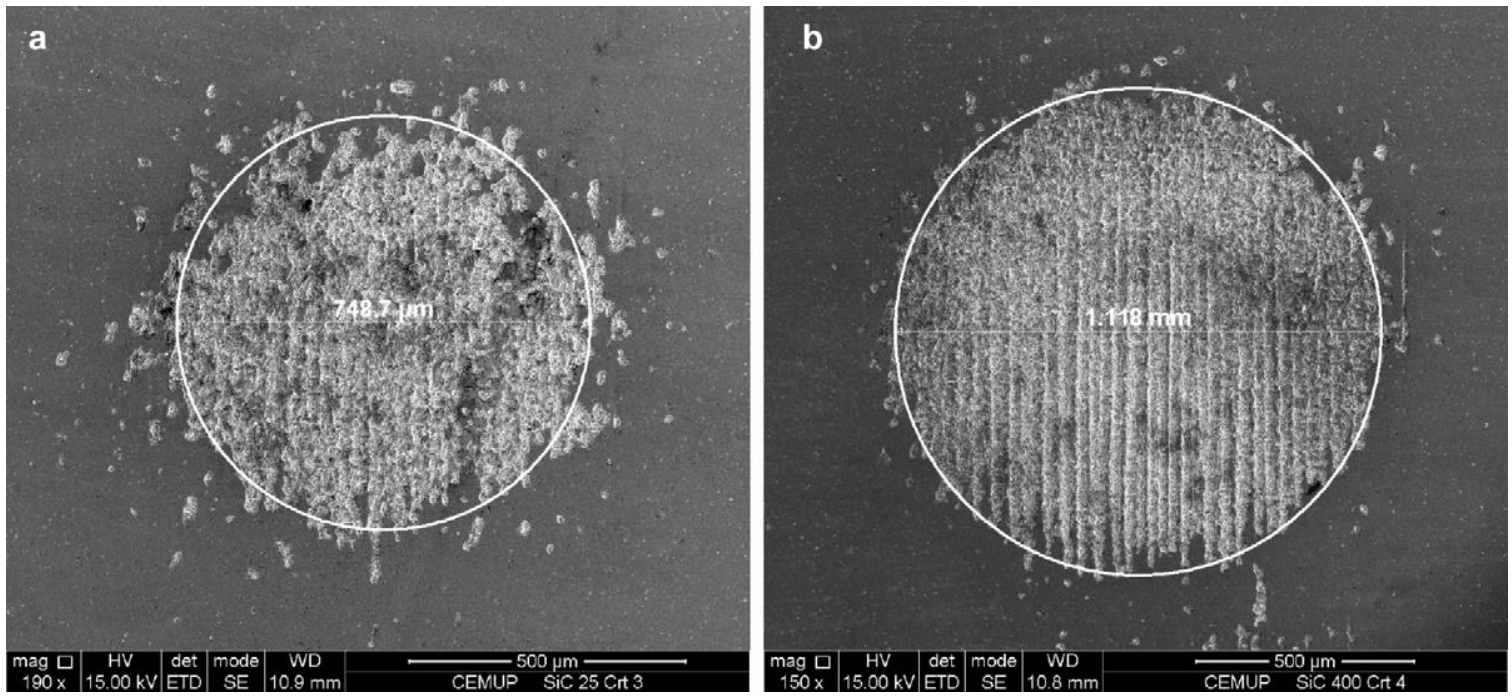

Fig. 6. Craters produced in the $\mathrm{TiB}_{2}$ coating (a) after 25 cycles ( $1.96 \mathrm{~m}$ sliding distance) with $\mathrm{SiC}$ F1000 abrasive particles and (b) after $400 \mathrm{cycles}$ ( $31.42 \mathrm{~m}$ sli ding distance) with the same abrasive. 

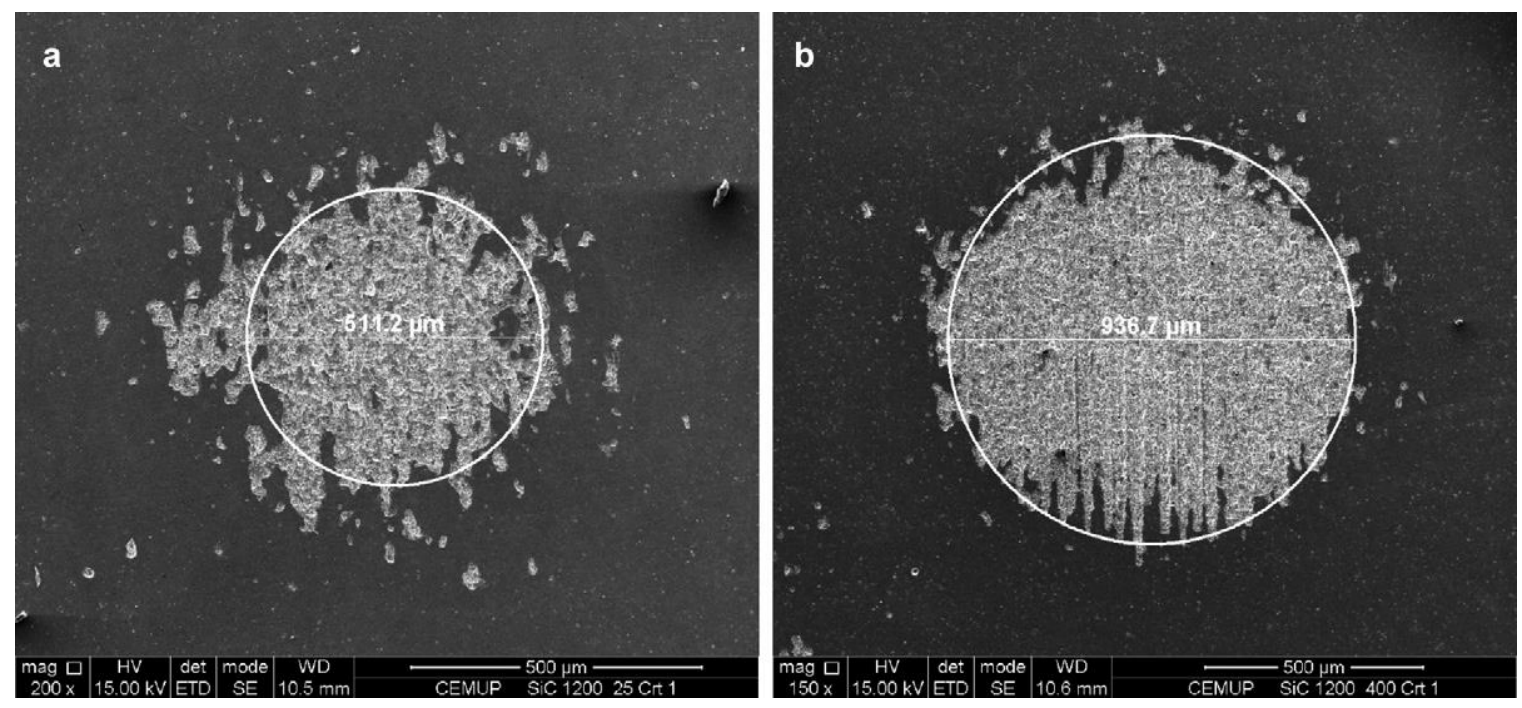

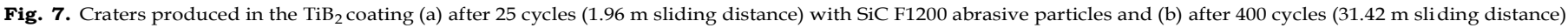
with the same abrasive.
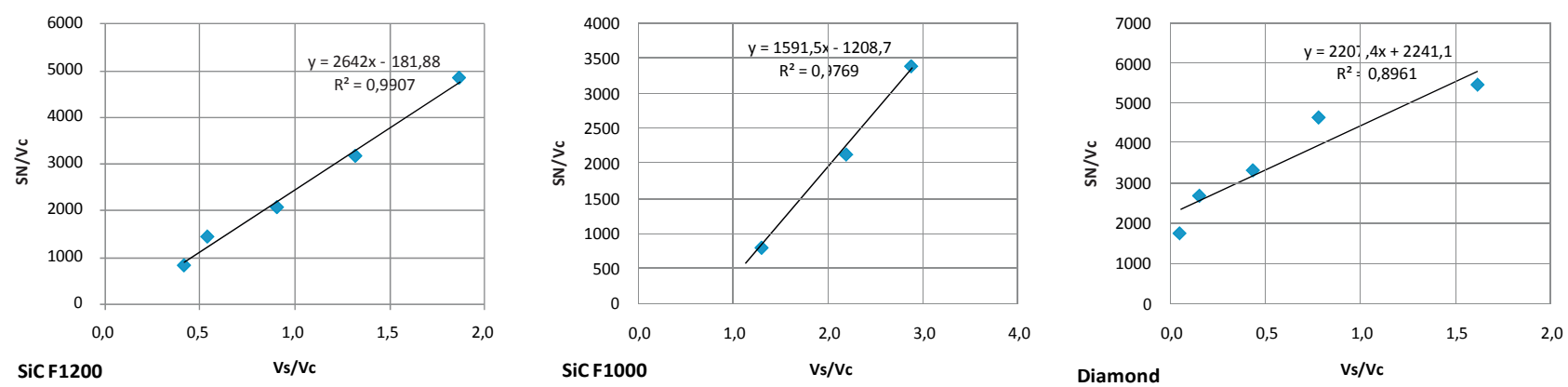

Fig. 8. Wear coefficient for $\mathrm{SiC}$ F1000, $\mathrm{SiC}$ F1200 and Diamond abrasive particles.

Regarding Table 5, and relating abrasives similar grain size $\left(\mathrm{Al}_{2} \mathrm{O}_{3}\right.$ and Diamond), it can be observed that wear coefficient is directly proportional to the " $H_{a} / H^{\prime \prime}$ ratio, relating the abrasive harness $(H a)$ with the coating hardness $(H)$. These results are in line with Hutchings work [22] but disagree with the conclusions drawn by Shipway and Hogg [17] under different conditions. Then, and attending that the same film is used for all the tests, it can be referred that the hardness is the main factor acting in the microabrasion wear system. Furthermore, the rounded shape of the alumina abrasive particles contributes, surely, to lower abrasive action than diamond particles.

When $\mathrm{SiC}$ abrasive particles are studied, presenting the same " $H_{a} / H$ " ratio, $\mathrm{TiB}_{2}$ coating presents lower wear resistance with $\mathrm{SiC}$ F1200 than SiC F1000. These results show that lower dimension of the SiC F1200 abrasive particles allows that a large number of particles take part effectively in the contact zone, increasing the micro-abrasion wear process. Large particles tend to turn around the ball, rolling sometimes between the sample surface and the ball, producing some damages in the overall border, but not participate effectively in the load carrying process. This effect can be observed regarding thecraterbordersproduced with $\mathrm{SiC}$ particles, asreferred and showed above. Then, the wear resistance of the $\mathrm{TiB}_{2}$ coating is six times higher for the SiC F1000 abrasive than SiC F1200.

\section{Conclusions}

After this work, some conclusion can be drawn, as following:
- $\mathrm{Al}_{2} \mathrm{O}_{3}$ abrasive particles shown low abrasivity, when compared with remaining abrasives tested. This can be attributed to its relatively low hardness and particles rounded contour.

- Micro-abrasion wear tests performed with diamond particles presented well-defined craters. Diamond shown high abrasivity. However, craters produced by $\mathrm{SiC}$ particles $\mathrm{F} 1000$ as well as F1200, are bigger than those formed by diamond particles;

- Heterogeneity of $\mathrm{SiC}$ particles used in this work, particularly SiC F1000, revealed to be harmful to micro-abrasion wear tests, resulting in ill-defined craters and lateral film detachments;

- The diameter of micro-abrasion wear craters and, consequently, the volume of material removed, allows to conclude that the hardness of the abrasive is very important but, there is not the only factor to contribute to severe micro-abrasion wear: when abrasive particles size increase, micro-abrasion wear is higher, not depending absolutely of the abrasive hardness;

- More accurate results can be achieved in micro-abrasion tests using, simultaneously, abrasives with high hardness and low grain size.

\section{Acknowledgments}

Authors would like to thank INEGI, Instituto de Engenharia Mecânica e Gestão Industrial (FE-UP). Authors also wish to thank 
Prof. Albano Cavaleiro and Dr. Manuel Evaristo (Ph.D.) of FCTUC for microindentation facilities availability.

\section{References}

[1] M.G.Gee, A. Gant, I. Hutchings, R. Bethke, K.Schiffman, K.van Aker, S. Poulat, Y Gachon, J. von Stebut, Progress towards standardization of ball cratering, Wear 255 (2003) 1-13.

[2] M.G. Gee, M.J. Wicks, Ball crater testing for the measurement of the unlubricated sliding wear of wear-resistant coatings, Surf. Coat. Technol. 133-134 (2000) 376-382

[3] K. Adachi, I.M. Hutchings, Sensivity of wear rates in the micro-scale abrasion test to test conditions and material hardness, Wear 258 (2005) 318 321.

[4] K. Adachi, K. Kato, N. Chen, Wear map of ceramics, Wear 203-204 (1997) 291-301.

[5] K. Kato, K. Adachi, Wear of advanced ceramics, Wear 253 (2002) 1097 1104.

[6] R.I. Trezona, D.N. Allsopp, I.M. Hutchings, Transitions between two-body and three-body abrasive wear: influence of test conditions in the microscale abrasive wear test, Wear 225-229 (1999) 205-214.

[7] R.I. Trezona, I.M. Hutchings, Three-body abrasive wear testing of soft materials, Wear 233-235 (1999) 209-221.

[8] D.N. Allsopp, R.I. Trezona, I.M. Hutchings, The effects of ball surface condition in the micro-scale abrasive wear test, Tribol. Lett. 5 (1998) 259-264.

[9] G.B. Stachowiak, G.W. Stachowiak, J.M. Brandt, Ball-cratering abrasion tests with large abrasive particles, Tribol. Int. 39 (2006) 1-11.

[10] K. Adachi, I.M. Hutchings, Wear-mode mapping for the micro-scale abrasion test, Wear 255 (2003) 23-29.

[11] K.L. Rutherford, I.M. Hutchings, A micro-abrasive wear test, with particular application to coated systems, Surf. Coat. Technol. 79 (1996) 231-239.
[12] P.HShipway, A mechanical model for particle motion in the micro-scale abrasion wear test, Wear 257 (2004) 984-991.

[13] C. Leroy, K.I. Schiffmann, K. van Acker, J. von Stebut, Ball cratering an efficient tool for 3 body micro-abrasion of coated systems, Surf. Coat. Technol. 200 (2005) 153-156.

[14] K.I. Schiffmann, R. Bethke, N. Kristen, Analysis of perforating and nonperforating micro-scale abrasion tests on coated samples, Surf. Coat. Technol. 200 (2005) 2348-2357.

[15] M.G. Gee, A.J. Gant, I.M. Hutchings, Y. Kusano, K. Sciffmann, K. van Acker, S. Poulat, Y. Gachon, J. von Stebut, P. Hatto, G. Plint, Results from an interlaboratory exercise to validate the micro-scale abrasion test, Wear 259 (2005) 2735.

[16] M.F.C. Andrade, R.P.M. Martinho, F.J.G. Silva, R.J.D. Alexandre, A.P.M. Baptista, Influence of the abrasive particles size in the micro-abrasion of TiAlSiN thin coatings, Wear 267 (2009) 12-18.

[17] P.H. Shipway, J.J. Hogg, Wear of bulk ceramics in micro-scale abrasion--the role of abrasive shape and hardness and its relevance to testing of ceramic coatings, Wear 263 (2007) 887-895.

[18] F.J.G.Silva, A.J.S. Fernandes, F.M. Costa, V. Teixeira, A.P.M. Baptista, E. Pereira, Tribological behaviour of CVD diamond films on steel substrates, Wear 255 (2003) 846-853.

[19] F.G. Silva, M.A. Neto, A.J.S. Fernandes, F.M. Costa, F.J. Oliveira, R.F. Silva, Adhesion and wear behaviour of NCD coatings on $\mathrm{Si}_{3} \mathrm{~N}_{4}$ by micro-abrasion tests, J. Nanosci. Nanotechnol. 9 (2009) 3938-3943.

[20] A.H. Jones, Micro-scale abrasive wear of silicon nitride, sialon- $\mathrm{TiB}_{2} \mathrm{com}-$ posites and D2 tool steel using a multiple load method, Wear 258 (2005) 942 952.

[21] Y Kusano, K. van Acker, I.M. Hutchings, Methods of data analysis for the micro-scale abrasion test on coated substrates, Surf. Coat. Technol. 183 (2004) 312-327.

[22] I.M. Hutchings, Tribology - Friction and Wear of Engineering Materials, Edward Arnold, London, 1992 